Prepared for the U.S. Department of Energy

under Contract DE-AC05-76RL01830

\title{
Development of Technology Readiness Level (TRL) Metrics and Risk Measures
}

\author{
DW Engel \\ AC Dalton \\ $\mathrm{K}$ Anderson \\ C Sivaramakrishnan \\ C Lansing
}

October 2012

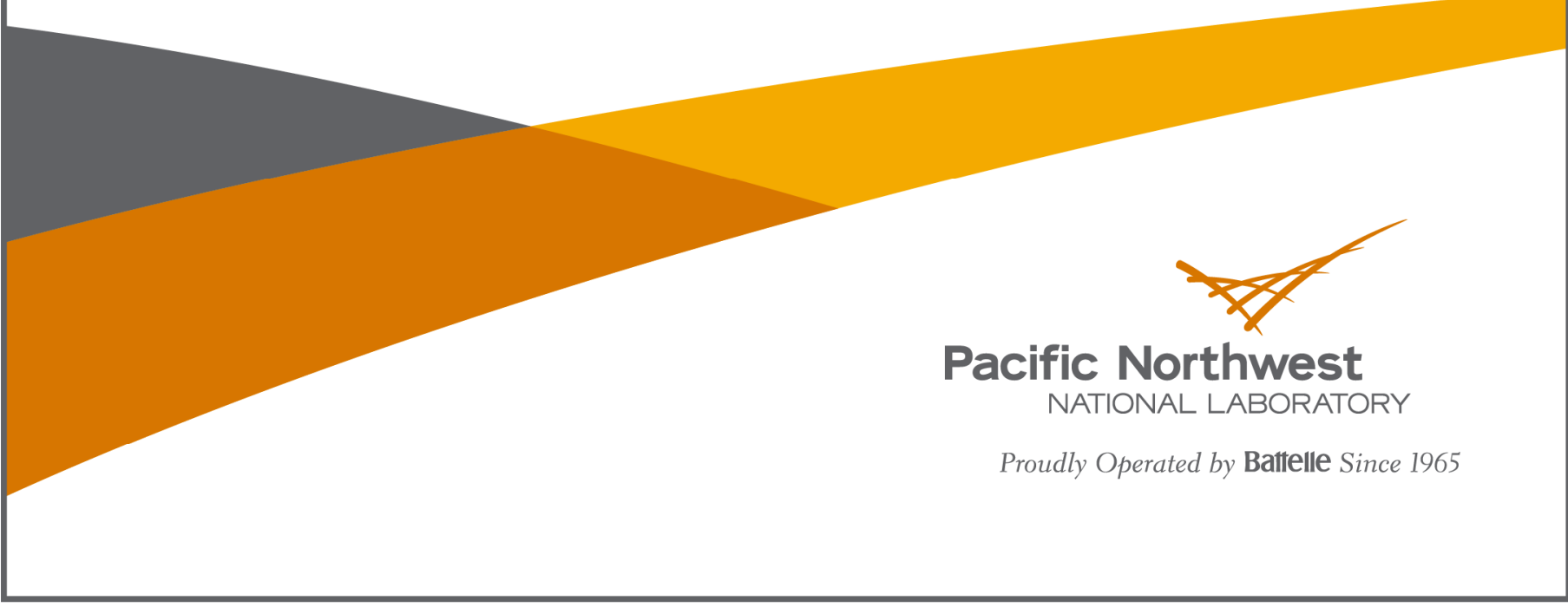




\title{
DISCLAIMER
}

This report was prepared as an account of work sponsored by an agency of the United States Government. Neither the United States Government nor any agency thereof, nor Battelle Memorial Institute, nor any of their employees, makes any warranty, express or implied, or assumes any legal liability or responsibility for the accuracy, completeness, or usefulness of any information, apparatus, product, or process disclosed, or represents that its use would not infringe privately owned rights. Reference herein to any specific commercial product, process, or service by trade name, trademark, manufacturer, or otherwise does not necessarily constitute or imply its endorsement, recommendation, or favoring by the United States Government or any agency thereof, or Battelle Memorial Institute. The views and opinions of authors expressed herein do not necessarily state or reflect those of the United States Government or any agency thereof.

\author{
PACIFIC NORTHWEST NATIONAL LABORATORY \\ operated by \\ BATTELLE \\ for the \\ UNITED STATES DEPARTMENT OF ENERGY \\ under Contract DE-AC05-76RL01830
}

Printed in the United States of America
Available to DOE and DOE contractors from the Office of Scientific and Technical Information,
P.O. Box 62, Oak Ridge, TN 37831-0062;
ph: (865) 576-8401
fax: $(865)$ 576-5728
email: reports@adonis.osti.gov

\begin{abstract}
Available to the public from the National Technical Information Service, U.S. Department of Commerce, 5285 Port Royal Rd., Springfield, VA 22161 ph: (800) 553-6847 fax: $(703) 605-6900$ email: orders@ntis.fedworld.gov online ordering: http://www.ntis.gov/ordering.htm
\end{abstract}

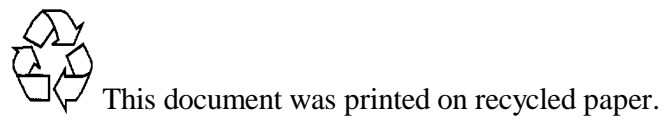




\title{
Development of Technology Readiness Level (TRL) Metrics and Risk Measures
}

\author{
DW Engel \\ AC Dalton \\ $\mathrm{K}$ Anderson \\ C Sivaramakrishnan \\ C Lansing
}

October 2012

Prepared for

the U.S. Department of Energy

under Contract DE-AC05-76RL01830

Pacific Northwest National Laboratory

Richland, Washington 99352 


\section{Contents}

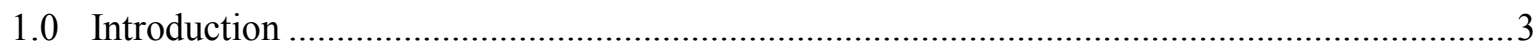

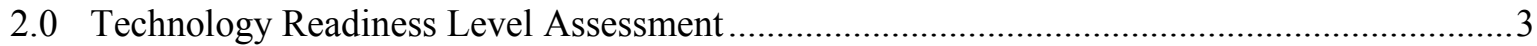

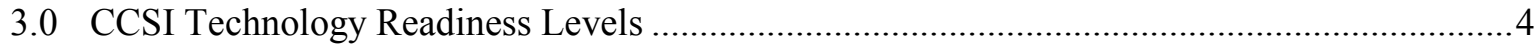

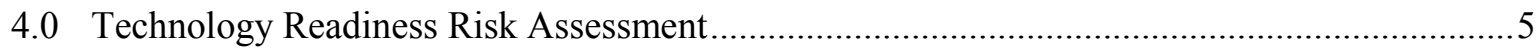

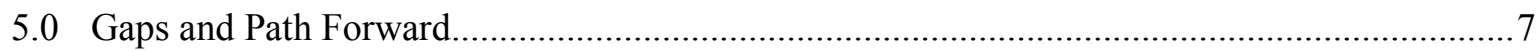

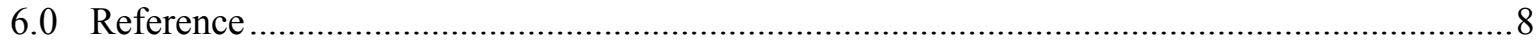

7.0 Appendix: CCSI Technology Readiness Level (TRL) Questionnaire....................................10

\section{Figures}

Figure 1 TRL uncertainty estimation (left side) and CDF (right side) assuming..........................6

Figure 2 TRL uncertainty estimation (left side) and CDF (right side), showing a comparison of assumed unertainty distributions (uniform, $\log _{10}$ Normal, triangle) ......................................

\section{Tables}

Table 1 Proposed TRL scale for carbon capture ......................................................................

Table 2 Example case showing probability of completing each TRL ............................................6

Table 3 Example case showing probability of completing each TRL ............................................ 


\subsection{Introduction}

Technology readiness measures the extent to which a technology is suited for deployment in a real operational environment. It is often used as a measure of risk associated with introducing new technologies into existing systems and standard operating procedures. For the Carbon Capture Simulation Initiative (CCSI), technology readiness assessment is an indispensable component of the technical risk model and the functional system performance analysis. Technology readiness assessment aims to evaluate the current carbon capture technologies' maturity against a set of requisite technical, programmatic, and manufacturing indicators identified from the relevant literature and experts to enable a successful and accelerated transition of carbon capture technologies from conceptualization, discovery, and development to eventual deployment. Technical readiness assessment also provides the basis for technical risk assessment and uncertainty quantification (Engel 2012).

In this report, we provide a brief overview of the current technology readiness assessment research, document the development of technology readiness levels (TRLs) specific to carbon capture technologies, describe the risk measures and uncertainty quantification approaches used in our research, and conclude by discussing the next steps that the CCSI Task 7 team aims to accomplish.

\subsection{Technology Readiness Level Assessment}

The current technology readiness research has two main focuses. In the psychometric-centered technology readiness studies, the research focus is to understand consumers' perception and beliefs about the maturity of a technology or product, and to investigate the relationship between the perception of technology readiness and product adoption and acceptance behavior by consumers (Parasuraman 2000; Lin 2007; Heslop et al. 2001). Technology readiness is conceptualized as consumers' beliefs (Lin et al. 2007) regarding a technology's usefulness, innovation, ease of application, and reliability (Parasuraman 2000). In Heslop et al. (2001) technology readiness assessment concentrates on attributes such as whether a technology is new, a major scientific breakthrough or core technology, whether background research is complete, and whether dominant alternatives exist (p. 382). In addition to the strength of the technology, adoption and commercialization depends on factors such as market appeal, available commercialization options, and managerial support. The common methodology used in these studies is consumer survey. Well-established survey instruments such as Karasurman's Technology Readiness Index (2000) have been widely used in the business sector.

Compared to consumer-oriented readiness research, technology-centered studies focus heavily on technological development and system integration rather than consumer's perception of technology maturity. This body of research examines the evolution of a technology from conceptualization to exploratory studies, laboratory experiments and demonstration, real operational demonstration, and then full integration. Technology readiness is evaluated by subdividing the technology development process into a number of clearly defined (but not necessarily linear) steps termed technology readiness levels (TRLs), and operationalizing each TRL with specific indicators to determine the readiness level of a technology in view of the overall readiness gradation scheme. In this line of research, effort has been undertaken to develop and refine the instruments that characterize the maturity of technologies. The earliest TRLs were developed by the National Aeronautics and Space Administration (NASA) in the late 1980s and have been subsequently updated, modified and adopted by NASA, DOD and other government agencies with world-wide adoption gaining momentum in early 2000 (see Mankins 1995; DHS 2009; Mankins 2009). Overtime TRL coverage has been expanded from exclusively technical indicators to include additional dimensions of readiness metrics such as hardware and software readiness, system readiness, programmatic readiness, manufacturing readiness, and integration readiness (see DHS 2009 for a review and Smith 2004). 


\subsection{CCSI Technology Readiness Levels}

The CCSI TRLs are similarly focused on the technology development, demonstration, and integration process of carbon capture technologies. Based on the relevant literature and multiple existing TRL instruments, the research team sought to develop TRLs that are specifically tailored toward assessing the state-of-the-art carbon capture technologies through computational modeling and simulation with the overarching objective of enabling accelerated commercialization and deployment of these technologies by the power industry (Engel 2012). The primary research goal for the TRL development is to utilize the risk analysis to produce robust uncertainty measures. Table 1 provides an overview of the proposed technology readiness scales for carbon capture technologies for a hybrid, solid sorbent capture system with a two-stage, counter-currently connecting bubbling fluidized bed adsorber and a moving bed regenerator for a $650 \mathrm{MWe}$ fossil fuel power plant. A total of nine levels were identified. They can be divided into three development stages. TRL 1, 2, and 3 measure the initial technology proof-of-concept development stage, TRL 4, 5, and 6 measure the readiness for simulated or near-real operational demonstrations with prototype models, and TRL 7, 8, and 9 measure the readiness for use in an operational environment and full-scale deployment.

Table 1 Proposed TRL scale for carbon capture

\begin{tabular}{|c|l|l|}
\hline \multicolumn{1}{|c|}{ Technology Readiness Level (TRL) } & \\
9 & Commercial operation in relevant environment & $650 \mathrm{MW}$ \\
\hline 7 & Commercial demonstration, full scale deployment in final form & $>100 \mathrm{MW}$ \\
\hline 6 & Fystem prototype in an operational environment & $10-50 \mathrm{MW}$ \\
5 & Component validation in relevant environment (coal plant) & $1 \mathrm{MW}$ \\
4 & Component validation tests in laboratory environment & $1 \mathrm{~kW}$ \\
\hline 3 & Analytical and experimental critical function proof-of-concept & \\
\hline 2 & Formulation of application & \\
1 & Basic principles & \\
\hline
\end{tabular}

EPRI 2011 (Freeman and Bhown) \& GAO 2010

To assess the readiness of carbon capture technologies, the team will recruit a group of experts from national laboratories, the academic community, and the power industry to provide assessment via a webbased questionnaire. Toward that end, the project team identified concrete readiness indicators for each of the nine technology readiness levels, and created the CCSI TRL Questionnaire (Appendix) for readiness assessment elicitation. This questionnaire is currently hosted on the CCSI website.

The CCSI TRLs have a few notable characteristics that help effectively address the shortfalls in the established TRL instruments. . A key criticism of the dominant TRLs is the failure to distinguish critical technology components from non-critical ones in readiness assessment. To cope with this limitation, the indicators incorporated into the questionnaire were selected exclusively on the basis of criticality. Only core technology components that are deemed necessary and sufficient for carbon capture technology development were selected whereas peripheral and nice-to-have features were excluded. While some of the CCSI TRL indicators are consistent with the ones outlined in DHS (2009) and Mankins (1995), the questionnaire also incorporated a number of indicators that measure the manufacturing and programmatic readiness for hardware at different readiness levels. This approach directly addresses the critique offered in Smith (2004) which pointed out that most TRLs fail to capture the multidimensional nature of the total 
technology development process, which goes beyond mere technical indicators. As a result, the CCSI TRL questionnaire includes indicators across three readiness dimensions: technology readiness level (TRL), manufacturing readiness level (MRL), and programmatic readiness level (PRL) to represent the multi-faceted development process for required of carbon capture technologies. In addition, although system integration was not designated as a separate TRL dimension, the technology readiness indicators include those that measure the readiness for system integration. With a comprehensive list of TRL indicators, the resulting questionnaire is more likely to generate a rich response from experts.

\subsection{Technology Readiness Risk Assessment}

A sufficient level of technology readiness is prerequisite for successful transition of research from an idea, to a laboratory experiment, and finally to a real operational application (Smith 2004; Lin et al. 2007). A plethora of technology readiness assessment research points out that risk associated with technology transition and adoption can be mitigated by the readiness of technologies. Research and conventional wisdom suggest a significant inverse relationship between technology readiness and risks of technology adoption (Heslop et al. 2007; Walczuch 2007): higher levels of technology readiness signal lower perceived risks; and low technology readiness denotes an increased level of risks (Smith 2004).

In past TRL risk assessments, risk calculation often leans toward conservatism. If a readiness assessment suggests that sub-components of a technology are at various TRLs, then the minimum readiness level is taken to represent the readiness level of the technology as a whole. An exemplary probabilistic assessment method based on TRLs conducted at Boeing follows this conservative approach (Mathews 2009). After the minimum level of technology readiness level is established based on a conservative estimation, then uncertainty bounds are estimated and statistical analysis is performed to visualize the risk. While this conservative approach is generally reflective of the risk-averse attitude well documented in the technology adoption literature, it tends to discount the nuanced and rich information provided by the evaluators. If all the elicited TRL assessment information can be incorporated into risk calculations, then resulting risk estimates could provide a more realistic assessment of the magnitude and spread of the risks. For CCSI, rather than providing a single number as a risk score/rating, we compute risk as cumulative probability distributions across all relevant TRLs with uncertainty bounds to estimate and visualize the risk. This approach brings as much information from the experts as possible to bear on risk assessment to generate a more realistic and information-driven result. The CCSI TRL assessment questionnaire consists of a series of multiple questions with binary outcomes (Yes/No). To transform this qualitative assessment into a quantitative assessment, we use the count of $\mathrm{Y} / \mathrm{N}$ responses for each readiness level and the binomial distribution to construct an uncertainty model as follows:

$$
P\left(T R L_{i}\right)=\left(\begin{array}{l}
n \\
k
\end{array}\right) p^{k}(1-p)^{n-k}
$$

Where $n$ is the number of questions for each specific TRL $(i), k$ is the number of "Yes" for each TRL, and $p$ is the probability parameter (set to 0.5 , which assumes that it is equally likely to get a yes or no for each question). The interpretation of Equation 1 is a probability or likelihood of a technology of being through a TRL, based on the number of questions that got a Yes answer.

So now that we have an estimate of the probability of being in a TRL, we need an estimate of uncertainty due to the lack of technology maturity. Research in different industries gives us the direction for this work (Mathews 2009; Lubkowski et al. 2010). As an example, the left plot in Figure 1 shows uncertainty bounds for each TRL. Using this example, it is desirable to progress to a higher TRL, since the 
uncertainty bound decreases as the level increases. Also shown in this plot is a distribution of uncertainty at TRL-5, assuming that the uncertainty is $\log _{10}$ Normally distributed. Assuming the uncertainty at each TRL is distributed Log Normal, the cumulative distribution (CDF) will look something like the right-side plot of Figure 1. The CDF shown in Figure 1 can then be used to simulate an uncertainty value for a given TRL.
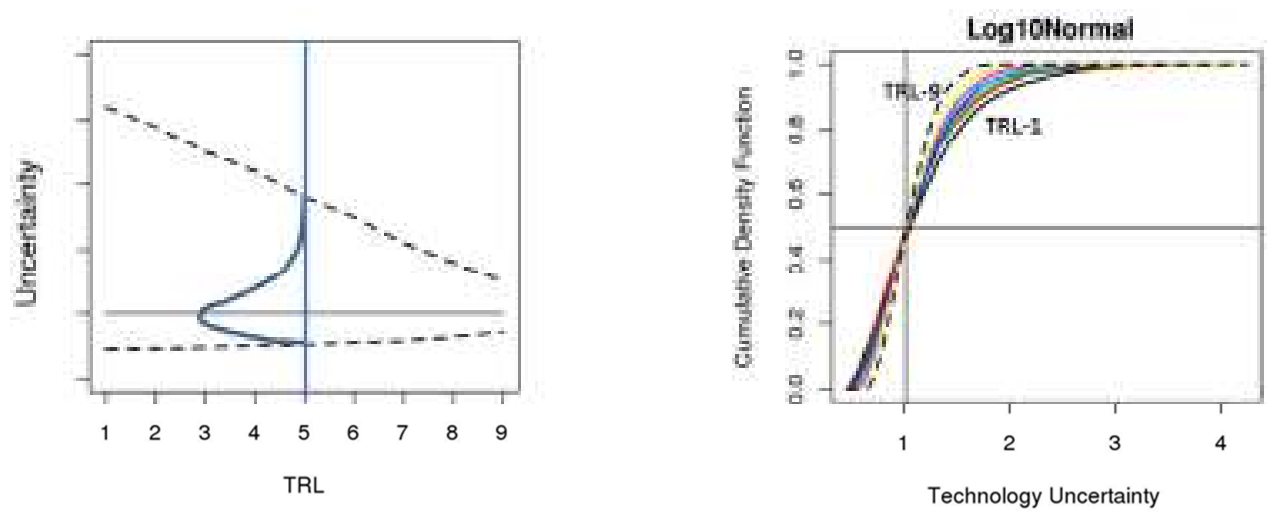

Figure 1 TRL uncertainty estimation (left side) and CDF (right side) assuming uncertainties are distributed as a Log Normal

The next step is to identify which TRL is appropriate. To accomplish this, we will model the TRL as a mixture problem. We will have an estimate for the probability of completing each level $\left(\alpha_{i}\right)$ and the uncertainty (CDF) for each level, $\mathrm{F}_{i}(x)$. To illustrate how this would work, a simple example is shown using the data in Table 1 . In this table, the probability of completing a TRL $\left(\alpha_{i}\right)$ is shown for each level.

Table 2 Example case showing probability of completing each TRL

\begin{tabular}{|l|l|l|l|l|l|l|l|l|l|}
\hline TRL & 1 & 2 & 3 & 4 & 5 & 6 & 7 & 8 & 9 \\
\hline P(TRL) & 1 & 1 & 1 & 0.8 & 0.2 & 0 & 0 & 0 & 0 \\
\hline
\end{tabular}

Using a conservative approach, we would use the uncertainty bounds for TRL-3, since this is the larges level that we estimate has been satisfied $(\mathrm{P}(\mathrm{TRL})=1.0)$. However, we would like to utilize the additional information about partially completing the other (higher) levels. This can be accomplished by using a combination (mixture) of all the TRL's. Assuming a linear mixture problem of each level, Equation 2 could be used to estimate the uncertainty $(\mathrm{U})$.

$$
U=\gamma_{1} F\left(x_{1}\right)+\gamma_{2} F\left(x_{2}\right)+\ldots+\gamma_{9} F\left(x_{9}\right)
$$

Typically, in a mixture problem the weights $\left(\gamma_{i}\right)$ sum to 1.0. However, in this example the weights, P(TRL), sum to $4.0(1+1+1+0.8+0.2)$. Also, since we have already satisfied the criteria for completing TRL 1-3, we can ignore the uncertainty estimates for TRL 1 and 2. Therefore, Equation 3 should satisfy all of these criteria.

$$
U=\left(1-\alpha_{4}\right)\left(1-\alpha_{5}\right) F\left(x_{3}\right)+\alpha_{4}\left(1-\alpha_{5}\right) F\left(x_{4}\right)+\alpha_{5} F\left(x_{5}\right)
$$

Using Equation 3 and the data in Table 1, new weights are calculated and shown in Table 2. Compared to the conservative approach, which would use only the uncertainty bounds for TRL-3 for a simulation study, using the results shown in Table 2 
Table 3 Example case showing probability of completing each TRL

\begin{tabular}{|c|c|c|c|c|c|c|c|c|c|}
\hline TRL & 1 & 2 & 3 & 4 & 5 & 6 & 7 & 8 & 9 \\
\hline P(TRL) & 0 & 0 & 0.16 & 0.64 & 0.2 & 0 & 0 & 0 & 0 \\
\hline CDF & 0 & 0 & 0.16 & 0.8 & 1 & 1 & 1 & 1 & 1 \\
\hline
\end{tabular}

So now we can extend the general mixture equation shown in Equation 2 and the adjusted equation (Equation 3) for all TRL's using the weights calculated (Table 2) using Equation 4.

$$
\begin{aligned}
& W_{j}=\alpha_{j} \prod_{i=j+1}^{9}\left(1-\alpha_{i}\right), j=1,2, \ldots, 8 \\
& W_{9}=\alpha_{9}
\end{aligned}
$$

The final step of the simulation is to randomly select the TRL for a given realization. This will be done by converting the weights calculated using Equation 4 into a cumulative distribution. This CDF is calculated using the following equation:

$$
C D F_{j}=\sum_{i=1}^{j} W_{i}
$$

The CDF for this example (Table 1) is shown in the bottom row of Table 2. This is then used with a random deviate $(r)$ generated from a uniform distribution $(0,1)$ and linear interpolation to simulate the TRL using Equation 6.

$$
T R L=\min (i) \text { such that }\left(C D F_{i}-r\right)>0
$$

Now that we have identified which TRL belongs to a given simulation, we can estimate an uncertainty value based on the uncertainty CDF (illustrated in Figure 2).

\subsection{Gaps and Path Forward}

In this report we review technology readiness research and describe the CCSI TRL questionnaire development and risk assessment effort. As mentioned earlier, the questionnaire is currently hosted online. As an immediate next step, we will improve the functionality of the user interface and online data analysis features. Parallel to the questionnaire user interface enhancement activities, we will also continue to refine the questionnaire instrument through iterative revisions with the task team as well as the multilaboratory project team. Recruitment of experts will also be undertaken to initiate the elicitation process for TRL assessment as well as for technical risk model development. CCSI Task 7 team seeks to provide a more comprehensive representation of factors that should be taken into considerations by the power industry which would enable decision makers to consider technology readiness probabilistically rather than deterministically and help them make more informed decision about carbon capture technology adoption. It is our hope that the resulting TRL assessment research and the risk model will fruitfully contribute to the development of a rigorous decision framework for accelerated carbon capture technology commercialization. 

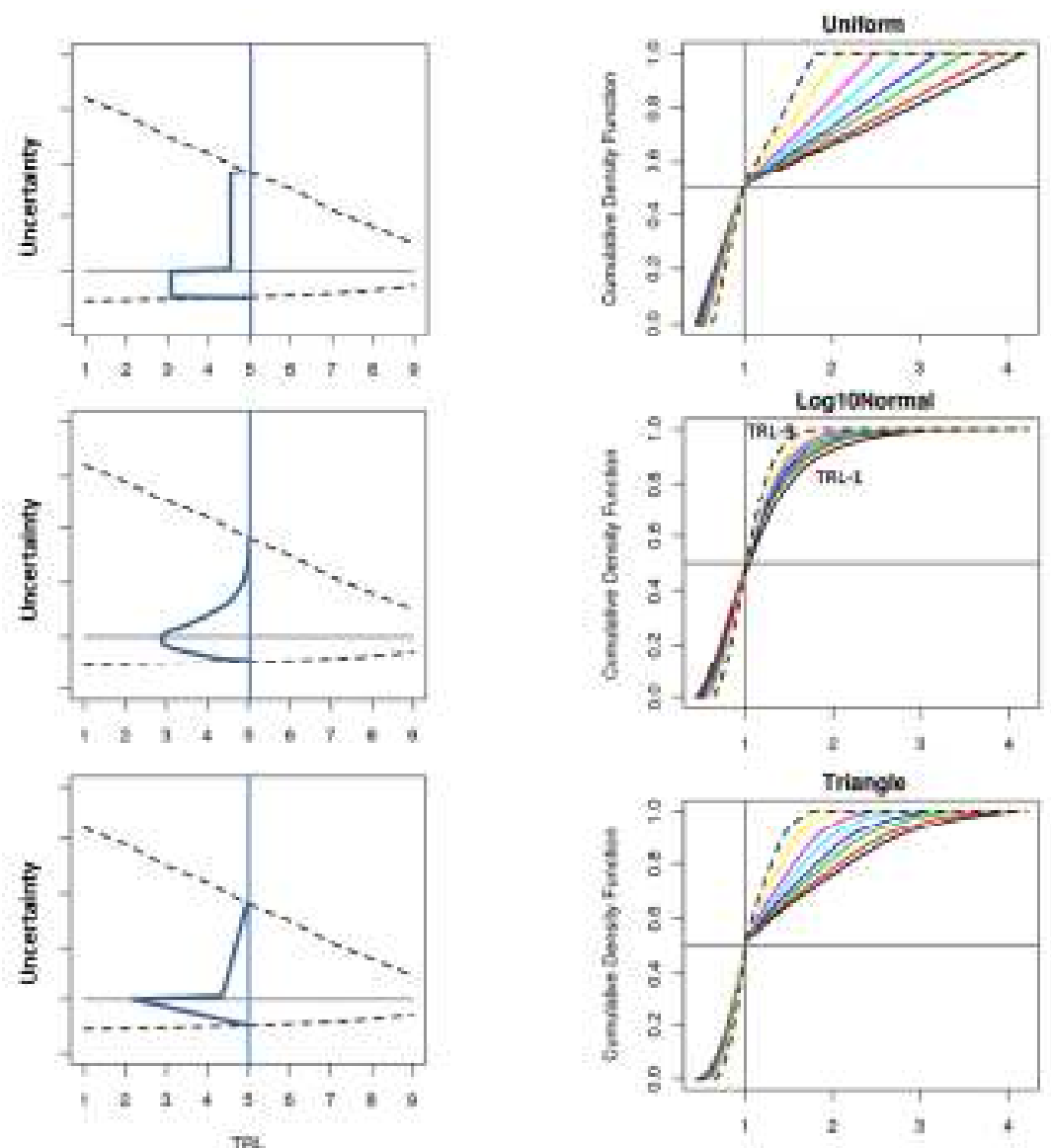

Figure 2 TRL uncertainty estimation (left side) and CDF (right side), showing a comparison of assumed unertainty distributions (uniform, $\log _{10}$ Normal, triangle)

\subsection{Reference}

DHS Homeland Security Institute. Department of Homeland Security Science and Technology Readiness Calculator, Arlington VA 2009.

Engel, D. W., Letellier, B., Edwards, B., LeClaire, R., \& Jones, E. (2012). New Technical Risk Management Development for Carbon Capture Process. Richland, WA: Pacific Northwest National Laboratory. Paper presented at 11th Annual Carbon Capture, Utilization and Sequestration Conference, Pittsburgh Pennsylvania, April 30-May 3.

Freeman, BC \& Bhown, AS, Assessment of the technology readiness of post-combustion CO2 capture technologies, Energy Procedia, 4, p.1791-1796, 2011.

Mathews, S, Valuing risky projects with real options. Research-Technology Management 52(5): 32-41, 2009.

Heslop, A., E. McGregor, and M. Griffith. Development of a Technology Readiness Assessment Measure: The Cloverleaf Mode. Journal of Technology Transfer 26(4): pp. 369-384, 2001. 
Lin, CH, HY Shih, and P. Sher. Integrating Technology Readiness into Technology Acceptance:

The TRAM Model. Psychology \& Marketing 24(7): 641-657, 2007.

Lubkowski, S, et al. Trade-off analysis of regenerative power source for long duration loitering Airship. Systems and Information Engineering Design Symposium (SIEDS), 2010 IEEE, vol., no., pp.25-30, 2010.

Mankins, JC, Technology Readiness Levels: A White Paper, NASA, Office of Space Access and Technology, Advanced Concepts Office, 1995.

Mankins, JC, Technology Readiness Assessments: A Retrospective, Acta Astroutica 65( 9-10): 12161223, 2009.

Parasuraman, A. Technology Readiness Index (TRI): A Mulitple-Item Scale to Measure Readiness to Embrace New Technologies. Journal of Service, Journal of Service Research 2(4): 307-320, 2000.

Smith, J. An Alterative to Technology Readiness Levels for Non-Developmental Item (NDI) Software. Technical Report CMU/SEI 2004-TR-013, Carnegie Mellon Software Engineering Institute, Pittsburg, PA, 2004.

United States General Accounting Office, Coal Power Plants: Opportunities Exist for DOE to Provide Better Information on the Maturity of Key Technologies to Reduce Carbon Dioxide Emissions, Washington D.C.: US GAO, GAO-10-675, 2010.

Rita Walczuch, R, J. Lemmink, and S. Streukens. The Effect of Service Employees' Technology Readiness on Technology Acceptance. Information \& Management 44: 206-215, 2007. 


\subsection{Appendix: CCSI Technology Readiness Level (TRL) Questionnaire}

Proposed TRL scale for carbon capture

\begin{tabular}{|c|c|c|}
\hline \multicolumn{3}{|c|}{ Technology Readiness Level (TRL) } \\
\hline 9 & Commercial operation in relevant environment & \\
\hline 8 & $\begin{array}{l}\text { Commercial demonstration, full scale deployment in final } \\
\text { form }\end{array}$ & $650 \mathrm{MW}$ \\
\hline 7 & System prototype in an operational environment & $100 \mathrm{MW}$ \\
\hline 6 & $\begin{array}{l}\text { Fully integrated pilot (prototype) tested in a relevant } \\
\text { environment }\end{array}$ & $10 \mathrm{MW}$ \\
\hline 5 & $\begin{array}{l}\text { Component validation in relevant environment (coal } \\
\text { plant) }\end{array}$ & $1 \mathrm{MW}$ \\
\hline 4 & Component validation tests in laboratory environment & $1 \mathrm{~kW}$ \\
\hline 3 & $\begin{array}{l}\text { Analytical and experimental critical function proof-of- } \\
\text { concept }\end{array}$ & \\
\hline 2 & Formulation of application & \\
\hline 1 & Basic principles & \\
\hline
\end{tabular}

+EPRI 2011 (Freeman and Bhown) \& GAO 2010

650 MW Solid Sorbent Hybrid Model

\section{TRL 1: Have basic principles been observed and reported?}

\begin{tabular}{|l|l|l|}
\hline Scale & & Comments \\
\hline & Has a reasonable process concept been proposed? & \\
\hline & Do basic principles (physical and chemical) support the concept? & \\
\hline & Have scientific observations been reported? & \\
\hline & Have mathematical formulations of concepts been developed? & \\
\hline
\end{tabular}


TRL 2: Has a concept or application been formulated?

\begin{tabular}{|l|l|l|}
\hline Scale & & Comments \\
\hline & Have functional requirements been determined? & \\
\hline & Have results of analytical studies been reported in peer- reviewed papers? & \\
\hline & Have potential design solutions been identified? & \\
\hline & $\begin{array}{l}\text { Have the basic components of the technology been identified and partially } \\
\text { characterized? }\end{array}$ & \\
\hline & Have performance predictions been documented for each component? & \\
\hline & $\begin{array}{l}\text { Have paper studies (studies done without laboratory work) confirmed the feasibility } \\
\text { of simple process simulations? }\end{array}$ & \\
\hline & Does preliminary analysis confirm basic scientific principles? & \\
\hline & Have experiments validating the concept been designed with synthetic data? & \\
\hline & Has preliminary qualitative risk analysis been documented? & \\
\hline
\end{tabular}

\begin{tabular}{|l|l|l|}
\hline \multicolumn{2}{|c|}{ TRL 3: Has analytical and experimental proof-of-concept been demonstrated in a laboratory environment? } \\
\hline Scale & \multicolumn{1}{|c|}{ Question } & Comments \\
\hline & Have experiments validated the predicted capability of technology components? & \\
\hline & Have analytical studies verified performance predictions and produced algorithms? & \\
\hline & Are the technology or system performance metrics established? & \\
\hline & Can science relevant to developing the technology be modeled or simulated? & \\
\hline & $\begin{array}{l}\text { Have technology or system performance characteristics been confirmed and } \\
\text { documented with representative data sets? }\end{array}$ & $\begin{array}{l}\text { Do experiments or modeling and simulation (M\&S) validate performance predictions } \\
\text { of technology capability? }\end{array}$ \\
\hline & $\begin{array}{l}\text { Do the results of technical application experiments verify the feasibility of such } \\
\text { applications? }\end{array}$ & $\begin{array}{l}\text { Does published research provide evidence for successful integration of technology } \\
\text { and system components? }\end{array}$ \\
\hline & Have design techniques been identified and/or developed? \\
\hline & Have scaling studies been initiated? \\
\hline
\end{tabular}


Has analysis of alternatives been completed?

Have programmatic risks been identified and mitigation strategies been documented?

\begin{tabular}{|l|l|l|}
\hline \multicolumn{2}{|l|}{ TRL 4: Has prototype-scale testing of equipment been completed in a laboratory environment? 1 kW } \\
\hline Scale & \multicolumn{1}{|c|}{ Question } & Comments \\
\hline & Have system requirements been finalized and documented? & \\
\hline & Have design requirements been derived from system requirements? & \\
\hline & Have system performance metrics been updated? & \\
\hline & Have scalable technology prototypes been produced? & \\
\hline & Has the performance of components been demonstrated at lab-scale? & \\
\hline & Has a draft process design been completed? & \\
\hline & $\begin{array}{l}\text { Have performance characteristics of a 1 kW lab-scale prototype been } \\
\text { demonstrated? }\end{array}$ & \\
\hline & $\begin{array}{l}\text { Have low-fidelity assessments of system integration and engineering been } \\
\text { completed? }\end{array}$ & \\
\hline & Does process simulation verify feasibility of the process at full scale? & \\
\hline & Have materials, processes, methods, and design techniques been identified? & \\
\hline & Are most system components available (laboratory surrogates in some cases)? & \\
\hline & Have integration studies been started? \\
\hline & Have initial cost drivers been identified? \\
\hline & Are scaling studies and architecture diagrams completed? \\
\hline $\begin{array}{l}\text { Has a formal risk management program been initiated and integrated with project } \\
\text { management? }\end{array}$ & \\
\hline
\end{tabular}




\begin{tabular}{|l|l|l|}
\hline TRL 5: Has pilot-scale testing been demonstrated in a relevant environment? 1 MW & Comments \\
\hline Scale & \multicolumn{1}{|c|}{ Question } & \\
\hline & Have system interface (internal and external) requirements been documented? & \\
\hline & Can unavailable system components be simulated using modeling and simulation (M\&S)? & \\
\hline & Has a pilot plant been developed at this scale? & \\
\hline & Are process measurements high fidelity? & \\
\hline & Does the pilot plant operate under realistic conditions? & \\
\hline & Have individual plant components been verified and validated through testing? & \\
\hline & Can all process specifications be simulated and validated in pilot plant? & \\
\hline & Has acceptance testing of individual components been performed? & \\
\hline & Has integration of modules/functions been demonstrated in a laboratory environment? & \\
\hline & Have quality and reliability issues been identified and documented (target levels may not yet be set)? & \\
\hline & Has system process design been finalized? & \\
\hline & Has systems engineering begun? & \\
\hline & Is the programmatic risk management plan documented? & \\
\hline & Has a configuration management plan been documented and implemented? & \\
\hline & Has formal review of all documentation been completed? & \\
\hline & Are materials, processes, methods, and design techniques at least moderately developed and verified? & \\
\hline
\end{tabular}




\begin{tabular}{|l|l|l|}
\hline \multicolumn{2}{|l|}{ TRL 6: Has prototype (semi-works pilot) engineering scale testing been demonstrated in a relevant environment? 10 MW } \\
\hline Scale & \multicolumn{1}{|c|}{ Question } & \multicolumn{1}{|c|}{ Comments } \\
\hline & Have system integration issues been addressed? & \\
\hline & Is the operational environment fully known and documented? & \\
\hline & Has prototype been tested in a simulated operational environment? & \\
\hline & Have performance characteristics been verified and validated in a simulated operational environment? & \\
\hline & Has prototype been tested in real operating environment? & \\
\hline & Has an inventory of external interfaces (e.g. material, solvent, supply chain) been completed? & \\
\hline & Are the components of the pilot plant functionally compatible in realistic problem-solving tests? & \\
\hline & Have control systems been verified and validated in pilot plant? & \\
\hline & Has engineering feasibility been fully demonstrated? & \\
\hline & Have engineering drawings and piping and instrumentation diagrams been finalized? & \\
\hline & Has collection of maintainability, reliability, and supportability data started? & \\
\hline & Have design to cost (DTC) goals been identified? & \\
\hline & Has system requirements specification document been completed? & \\
\hline & Are all changes controlled/documented using configuration management? & \\
\hline & Has the final technical report been completed? & \\
\hline
\end{tabular}




\begin{tabular}{|c|l|c|}
\hline TRL 7: Has equipment/process successfully operated in the relevant operational environment? 100 MW \\
\hline Scale & \multicolumn{1}{|c|}{ Question } & Comments \\
\hline & Has process equipment been tested individually under stressed and anomalous conditions? & \\
\hline & Are modeled components representative of production components? & \\
\hline & Has operational testing of the process in relevant environment been completed? & \\
\hline & Is data for Reliability, Maintainability, and Supportability analysis available? & \\
\hline & Are process equipment and materials available? & \\
\hline & Do prototypes represent actual form, fit, and function? & \\
\hline & Have software algorithms been verified and validated with existing systems? & \\
\hline & Is scaling completed? & \\
\hline
\end{tabular}

\begin{tabular}{|c|l|l|}
\hline TRL 8: Has the actual unit successfully operated in a limited operational environment 650 MW & Comments \\
\hline Scale & \multicolumn{1}{|c|}{ Question } & \\
\hline & Are all technology/system components form, fit, and function compatible? & \\
\hline & Is technology/system form, fit, and function compatible with operational environment? & \\
\hline & Has technology/system form, fit, and function been demonstrated in operational environment? & \\
\hline & Has technical Developmental Test and Evaluation (DT\&E) documentation been completed? & \\
\hline & Are all materials in production and readily available? & \\
\hline & Has maintainability, reliability, and supportability data collection been completed? & \\
\hline & Is maintenance documentation completed and under configuration control? & \\
\hline & Have final architecture diagrams been completed? & \\
\hline
\end{tabular}




\begin{tabular}{|c|l|l|}
\hline \multicolumn{2}{|c|}{ TRL 9: Has the actual unit successfully operated in the full operational environment (hot operations)? } & 650 MW \\
\hline Scale & \multicolumn{1}{|c|}{ Question } & Comments \\
\hline & Does technology/system function as defined in Operational Concept document? & \\
\hline & Has technology/system been deployed in intended operational environment? & \\
\hline & Has technology/system been fully demonstrated? & \\
\hline & Has Operational Test and Evaluation (OT\&E) been successfully completed and documented? \\
\hline & Have design to cost (DTC) goals been met? & \\
\hline & Have safety/adverse effects issues been identified and mitigated? & \\
\hline & Has all programmatic documentation been completed? & \\
\hline
\end{tabular}




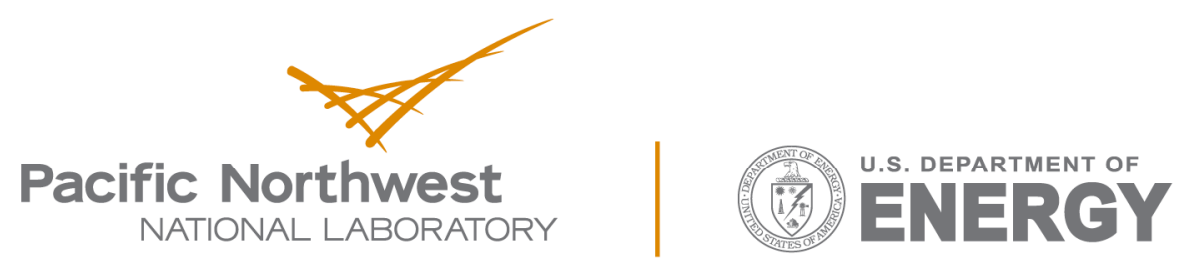

Proudly Operated by Battelle Since 1965

902 Battelle Boulevard

P.O. Box 999

Richland, WA 99352

1-888-375-PNNL (7665)

www.pnnl.gov 